\title{
Grange syndrome
}

INSERM

\section{Source}

INSERM. (1999). Orphanet: an online rare disease and orphan drug data base. Grange syndrome. ORPHA:79094

Grange syndrome is characterised by stenosis or occlusion of multiple arteries (including the renal, cerebral and abdominal vessels), hypertension, brachysyndactyly, syndactyly, increased bone frag ility, and learning difficulties or borderline intellectual deficit. Congenital heart defects were also reported in some cases. 